\title{
The Association Between Long- Term Acenocoumarol Treatment and Vitamin D Deficiency
}

\begin{abstract}
Jolanta Sawicka-Powierza ${ }^{1,2 *}$, Jerzy Konstantynowicz ${ }^{3}$, Ewa Jablonska ${ }^{4}$, Beata Zelazowska-Rutkowska ${ }^{5}$, Wojciech Jelski ${ }^{6}$, Pawel Abramowicz ${ }^{3}$, Caroline Sasinowski ${ }^{7}$ and Slawomir Chlabicz ${ }^{1}$
\end{abstract}

\begin{abstract}
'Department of Family Medicine, Medical University of Bialystok, Bialystok, Poland, ${ }^{2}$ Department of Haematology, Medical University of Bialystok, Bialystok, Poland, ${ }^{3}$ Department of Pediatrics, Rheumatology, Immunology, and Metabolic Bone Diseases, Medical University of Bialystok, Bialystok, Poland, ${ }^{4}$ Department of Immunology, Medical University of Bialystok, Bialystok, Poland, ${ }^{5}$ Department of Pediatric Laboratory Diagnostics, Medical University of Bialystok, Bialystok, Poland, ${ }^{6}$ Department of Biochemical Diagnostics, Medical University of Bialystok, Bialystok, Poland, ${ }^{7}$ University Clinical Hospital, Medical University of Bialystok, Bialystok, Poland
\end{abstract}

Objective: Both vitamin D and K2 are involved in a number of metabolic processes, including bone metabolism; however, associations between the vitamins are not fully understood. The aim of the study was to evaluate serum concentrations of

OPEN ACCESS

Edited by:

Giovanna Mantovani, Università degli Studi di

Milano, Italy

Reviewed by:

Alfredo Scillitani,

Casa Sollievo della Sofferenza (IRCCS), Italy Elisa Cairoli,

Università degli Studi

di Milano, Italy

*Correspondence: Jolanta Sawicka-Powierza jolasawicka@gmail.com

Specialty section: This article was submitted to Systems and Translational Endocrinology,

a section of the journal Frontiers in Endocrinology

Received: 18 January 2018 Accepted: 20 April 2018 Published: 04 May 2018

Citation:

Sawicka-Powierza J, Konstantynowicz J, Jablonska E, Zelazowska-Rutkowska B, Jelski W, Abramowicz P, Sasinowski $C$ and

Chlabicz S (2018) The Association Between Long-Term Acenocoumarol Treatment and Vitamin D Deficiency.

Front. Endocrinol. 9:226.

doi: 10.3389/fendo.2018.00226 25-hydroxyvitamin $\mathrm{D}[25(\mathrm{OH}) \mathrm{D}]$ in adult patients receiving long-term acenocoumarol (AC) treatment.

Participants and methods: In this cross-sectional study, 58 Caucasian patients (31 women, 27 men) with a median age of 65 years receiving long-term AC therapy were evaluated and compared with 35 age- and gender-matched healthy controls. The AC treatment was used due to recurrent venous thromboembolism (34.5\%), atrial fibrillation (31\%), or mechanical heart valve prostheses (34.5\%). Medical records and a questionnaire were used to obtain information about chronic diseases, smoking habits, and the duration of therapy and weekly dose of AC. Anthropometric measurements were performed, and serum concentration of $25(\mathrm{OH}) \mathrm{D}$ and total alkaline phosphatase (ALP) activity were measured.

Results: Among the 58 patients receiving long-term AC treatment, a high proportion (46.6\%) demonstrated significant vitamin D deficiency with concentrations of $25(\mathrm{OH})$ D lower than $20 \mathrm{ng} / \mathrm{mL}$. The median concentration of $25(\mathrm{OH}) \mathrm{D}$ in subjects receiving AC was significantly lower compared to the control group [20.4 (17.4; 26.1) vs. 28.2 (24; 32.7); $p<0.001]$. No differences were found between women and men receiving $A C$ therapy. In patients receiving $A C$, a negative correlation was found between the concentration of $25(\mathrm{OH}) \mathrm{D}$ and the weekly dose of $\mathrm{AC}(r=-0.337, p=0.01)$. Patients with concentrations of $25(\mathrm{OH}) \mathrm{D}<20 \mathrm{ng} / \mathrm{mL}$ were found to have a significantly higher median dose of $\mathrm{AC}$, compared to those with concentrations of $25(\mathrm{OH}) \mathrm{D} \geq 20 \mathrm{ng} / \mathrm{mL}$ [21 (17; 31) vs. $17(12 ; 28) ; p=0.045]$.

Conclusion: In conclusion, treatment with $\mathrm{AC}$ is associated with low 25-hydroxyvitamin $\mathrm{D}$ levels, although the path leading to this phenomenon is not entirely clear. Long-term administration of $A C$ in adults may increase the risk of chronic vitamin $D$ deficiency, thus, effective supplementation of vitamin $D$ in these individuals needs careful consideration. 


\section{INTRODUCTION}

Vitamin D synthesized in the skin or obtained from the diet is biologically inactive. Enzymatic conversion in the liver and kidney is required for its activation. Cholecalciferol [vitamin $\mathrm{D}(3)$ ], inherently present in animals, is converted to calcifediol (25-hydroxycholecalciferol) in the liver, whereas ergocalciferol [vitamin $\mathrm{D}(2)$ ], naturally found in plants, is converted to 25-hydroxyergocalciferol. These two vitamin D metabolites [called 25-hydroxyvitamin D or $25(\mathrm{OH}) \mathrm{D}$ ] are measured in serum to determine vitamin D status (1). $25(\mathrm{OH}) \mathrm{D}$ is further hydroxylated by the kidneys to form calcitriol (1,25-dihydroxycholecalciferol), the biologically active form of vitamin D (2). The presence of 1- $\alpha$-hydroxylase has been confirmed in bone tissue; hence bone itself is regarded as a source of the active form of vitamin D (3). Vitamin D exerts direct effects on various populations of bone cells, and functions indirectly by regulating both calcium-phosphate homeostasis (4) and the expression of parathormone (5). Vitamin D stimulates proliferation and differentiation of osteoblasts and osteoclasts (6), regulates the expression of numerous genes in the bone cell population (7), plays a role in the synthesis of key proteins secreted by osteoblasts, and inhibits apoptosis of osteoblasts (8). Vitamin D also regulates the expression of proteins involved in intestinal calcium absorption and calcium reabsorption by renal tubules, which ensures adequate mineralization of osteoid. Thus, bone metabolism largely depends on the biological action and adequate levels of vitamin D.

Experimental and observational studies, as well as clinical trials, indicate that insufficient intake of vitamin $\mathrm{K} 2$ and/or long-term treatment with vitamin $\mathrm{K}$ antagonists (VKAs) are related to bone metabolism disorders and arterial calcification (9-13). The specific mechanism of how vitamin K2 impacts bone metabolism has yet to be fully explained and understood. It is known that dietary calcium is absorbed from the digestive tract with the participation of vitamin $\mathrm{D}$, while both vitamins, $\mathrm{D}$ and $\mathrm{K} 2$, are responsible for the production of the active form of osteocalcin, an integral protein involved in the synthesis of bone matrix and binding of calcium ions (14). Interestingly enough, an excess of calcium intake, particularly derived from supplementation, when combined with vitamin K2 deficiency, may result in the deposition of calcium in blood vessels (arterial calcification) and may increase the risk of soft tissue calcification (15). VKAs, including acenocoumarol (AC), suppress the synthesis of vitamin K-dependent proteins. Instead, alternative pathways are initiated resulting in the formation of undercarboxylated Gla proteins. In the bone, this results in the synthesis of the functionally inactive form of osteocalcin (16). The information above confirms the existence of links between vitamins D, K2, and bone metabolism, and could explain the potential pathogenic role of VKAs in impaired bone metabolism. For this reason, the possible connection between the use of VKA and vitamin D status may

Abbreviations: AC, acenocoumarol; ALP, serum total alkaline phosphatase; BMI, body mass index; NS, non significant; VKA, vitamin K antagonist; 25(OH)D, 25-hydroxyvitamin D. also be worth investigating in the context of chronic diseases and treatment.

According to the current guidelines, hypovitaminosis $\mathrm{D}$ is diagnosed by measuring serum concentration of 25-hydroxyvitamin $\mathrm{D}\{[25(\mathrm{OH}) \mathrm{D}]$; calcidiol $\}$, the most commonly accepted indicator of vitamin D status. Levels of $25(\mathrm{OH}) \mathrm{D}$ below $20 \mathrm{ng} / \mathrm{mL}$ $(50 \mathrm{nmol} / \mathrm{L})$ are indicative of a deficiency and levels of $20-30 \mathrm{ng} / \mathrm{mL}$ (50-75 nmol/L) indicate an insufficiency, although the definition of deficiency and insufficiency remain a subject of discussion $(17,18)$. Several negative skeletal effects and bone mineral disorders may be attributed to both vitamin D deficiency and suboptimal vitamin K2 levels. It has been reported that vitamin $\mathrm{K} 2$, combined with vitamin $\mathrm{D}$, increases bone mineral density more efficiently than vitamin K2 alone (19). Some study has also shown that vitamin K2 supplementation improves hip bone geometry and bone strength indices among postmenopausal women (20). Given that the effects of vitamin K2 may be generally beneficial for bone health, the suppression of vitamin $\mathrm{K} 2$ by VKA may potentially lead to impairment of bone metabolism and, therefore, a deteriorated skeletal status. However, as there are still conflicting reports and inconsistent data, the question arises whether long-term use of VKAs with coexisting vitamin $\mathrm{D}$ deficiency may have clinical implications or be a risk for patients.

The objective of the study was to evaluate vitamin D status expressed as serum concentration of 25-hydroxyvitamin D $[25(\mathrm{OH}) \mathrm{D}]$ in adult patients receiving long-term AC treatment.

\section{MATERIALS AND METHODS}

\section{Participants and Study Protocol}

The cross-sectional study was conducted among adult patients treated with AC and healthy individuals recruited from the population of 5,834 people of a primary care practice. Participants' data were initially retrieved from an electronic database and medical records of the primary care facility taking part in the study. The obtained data contained information about age, gender, indications for anticoagulant treatment, and type of administered medication. Patients were previously qualified for AC prophylaxis due to recurrent venous thromboembolism, atrial fibrillation, or mechanical heart valve prostheses. The age- and gender-matched control group was recruited from the healthy population of the primary care practice using a random numbers table. The inclusion criteria consisted of written informed consent and duration of $\mathrm{AC}$ treatment longer than 3 months. Based on a questionnaire and medical records, participants with chronic diseases (i.e., chronic renal, gastrointestinal, liver, and endocrine diseases), those receiving treatment affecting vitamin D status/metabolism (i.e., anticonvulsants, systemic glucocorticosteroids), and those taking vitamin D and/or K2 supplements, were excluded from the study.

Seventy-two patients treated with AC, and 70 healthy subjects (controls) were invited to the study. Fourteen patients receiving $\mathrm{AC}$, as well as 22 controls, did not meet all eligibility criteria and were excluded. Additionally, 13 healthy subjects refused to participate. Ultimately, 58 Caucasian patients ( 27 males, 31 females) 
with median age 65 years receiving long-term AC treatment for recurrent venous thromboembolism $(n=20 ; 34.5 \%)$, atrial fibrillation $(n=18 ; 31 \%)$, and mechanical heart valve prostheses $(n=20 ; 34.5 \%)$ were enrolled into the study. Thirty-five healthy subjects (16 males, 19 females) with median age 61 years constituted the control group. Evaluation of all participants taking part in the study was done exclusively on the basis of medical records and a questionnaire. All participants were screened for chronic diseases and therapies known to affect vitamin D status. None of the participants had been supplemented with vitamin $\mathrm{D}$ and/or fish oil or vitamin $\mathrm{K}$ prior to and during the study. Study subjects were asked about the duration and weekly dose of AC treatment, smoking habits (past and current), time of menopause (if applicable), and the time spent outdoors. The majority of the participants (66 individuals; $71 \%$ ) were people working in their profession, while others in the sample were not older than 80 years old. Furthermore, neither the patients receiving AC nor any of the controls had conditions that would have made ambulating difficult. Finally, time spent outdoors was comparable among subjects included in the patient and the control group.

The study protocol and procedures were approved by the Ethics Committee of the Medical University of Bialystok (No R-I-002/88/2013).

\section{Measurements}

Blood was collected from the study subjects in the winter season (between January and March) to avoid seasonal variations of vitamin D concentration. Blood samples were collected before 9:00 a.m. on the day of the interview after overnight fasting. All samples were centrifuged within $60 \mathrm{~min}$ from blood draw and sera were stored at $-70^{\circ} \mathrm{C}$ until measurement.

The Elecsys Vitamin $\mathrm{D}(3)$ (25-OH) immunoassay was used for the quantitative determination of 25-hyroxyvitamin $\mathrm{D}(3)$ on cobas e immunoassay analyzer (Roche Diagnostics, Indianapolis, IN, USA). Activity of alkaline phosphatase was measured by colorimetric method (Abbott Laboratories, Abbott Park, Illinois, USA) with para-nitrophenyl phosphate as substrate. The reaction was monitored at $404 \mathrm{~nm}$ on an Architect ci8200 analyzer (Architect System, Abbott Laboratories, IL, USA).

Standing height and body weight were measured using standard anthropometric methods (wall-mounted stadiometer, electronic scale; Seca, Germany) and body mass index (BMI) was calculated using the standard formula.

\section{Statistical Analyses}

Statistical analyses were performed using the Statistical Package for the Social Sciences (SPSS), version 11.5. The Shapiro-Wilk test was used to examine normal distribution. Since the data were not normally distributed, the results were presented as a median, 25th and 75th percentile. Nonparametric $t$-test and Mann-Whitney $U$ test were applied for comparison between groups. $\mathrm{Chi}^{2}$ test was used for qualitative data. Correlations between parameters were evaluated with Spearman's rank correlation coefficient. For the calculations, $p<0.05$ was adopted as the level of statistical significance.

\section{RESULTS}

No differences in terms of age, gender, BMI, time elapsed, since menopause (females), smoking habits, and ALP activity were found between subjects receiving AC and the control group. All participants had ALP activity within the normal range (normal values: $37-110 \mathrm{IU} / \mathrm{L})$. The median concentration of $25(\mathrm{OH}) \mathrm{D}$ in patients treated with $\mathrm{AC}$ was significantly lower compared to controls $(p<0.001)$ (Table 1). Anthropometric and biochemical parameters did not significantly differ between the groups of patients receiving AC prophylaxis for recurrent venous thromboembolism, atrial fibrillation, and mechanical heart valve prostheses. No differences between women and men receiving AC were found with regards to the studied variables.

Figure 1 presents the proportion of subjects with $25(\mathrm{OH})$ D level below $20 \mathrm{ng} / \mathrm{mL}$, between 20 and $30 \mathrm{ng} / \mathrm{mL}$, and those above $30 \mathrm{ng} / \mathrm{mL}$. It was found that $27(46.5 \%)$ individuals receiving $\mathrm{AC}$ had vitamin $\mathrm{D}$ deficiency, i.e., 25(OH)D levels below $20 \mathrm{ng} / \mathrm{mL}$. Such deficiency was observed in only $2(5.7 \%)$ control subjects. Levels of 25(OH)D between 20 and $30 \mathrm{ng} / \mathrm{mL}$ were found in $24(41.4 \%)$ subjects treated with $\mathrm{AC}$, and in 20 (57.1\%) control subjects. Normal $25(\mathrm{OH}) \mathrm{D}$ values, defined as higher than $30 \mathrm{ng} / \mathrm{mL}$, were found only in 7 (12.1\%) patients receiving AC treatment and in $13(37.2 \%)$ controls. Patients receiving $\mathrm{AC}$ had a significantly larger proportion of decreased $25(\mathrm{OH}) \mathrm{D}$ concentration compared to controls $(p<0.001)$.

Among patients receiving $\mathrm{AC}$ treatment, a negative correlation was found between the weekly dose of $\mathrm{AC}$ and serum concentration of $25(\mathrm{OH}) \mathrm{D}(r=-0.337 ; p=0.01)$ (Figure 2), and between the weekly dose of AC and age $(r=-0.352 ; p=0.007)$. Also, a positive correlation between ALP activity and age was observed ( $r=0.272 ; p=0.039)$.

In the control group, a negative correlation was found between 25(OH)D level and age, and between 25(OH)D and the time, since menopause $(r=-0.395 ; p=0.019$ and $r=-0.717$; $p=0.003$, respectively). ALP activities positively correlated with age $(r=0.403 ; p=0.017)$.

Among patients receiving AC, the studied parameters were compared between two groups of patients; those with a threshold

TABLE 1 | Basic characteristics of study participants.

\begin{tabular}{lccc}
\hline Characteristics & $\begin{array}{c}\text { Subjects } \\
\text { receiving } \\
\text { acenocoumarol }\end{array}$ & $\begin{array}{c}\text { Control } \\
\text { subjects }\end{array}$ & $\boldsymbol{p}$ \\
\hline Number, $n$ & 58 & 35 & \\
Age, years & $65(59 ; 73)$ & $61(59 ; 72)$ & $\mathrm{NS}$ \\
Gender (male/female), $n(\%)$ & $27(46.6) / 31(53.4)$ & $16(45.7) / 19(54.3)$ & $\mathrm{NS}$ \\
Body mass index, kg/m & $28.1(24.9 ; 31.3)$ & $27.3(24.4 ; 29.4)$ & $\mathrm{NS}$ \\
Post-menopause, years & $15(8.8 ; 23.3)$ & $9(6 ; 23)$ & $\mathrm{NS}$ \\
Smokers/non-smokers, $n(\%)$ & $11(19) / 47(81)$ & $4(11.4) / 31(88.6)$ & $\mathrm{NS}$ \\
Duration of AC treatment, & $8(6.8 ; 12.3)$ & 0 & $<0.001$ \\
years & $19(14 ; 28)$ & 0 & $<0.001$ \\
Weekly dose of AC, mg & $20.4(17.4 ; 26.1)$ & $28.2(24 ; 32.7)$ & $<0.001$ \\
Serum 25(OH)D, ng/mL & $61(54.3 ; 75)$ & $54(51 ; 68)$ & $\mathrm{NS}$ \\
ALP, IU/L & & & \\
\hline
\end{tabular}

Results are shown as median and quartiles (Q1; Q3).

To convert values for 25-hydroxyvitamin $D$ to $\mathrm{nmol} / \mathrm{L}$, multiply by 2.5 . 


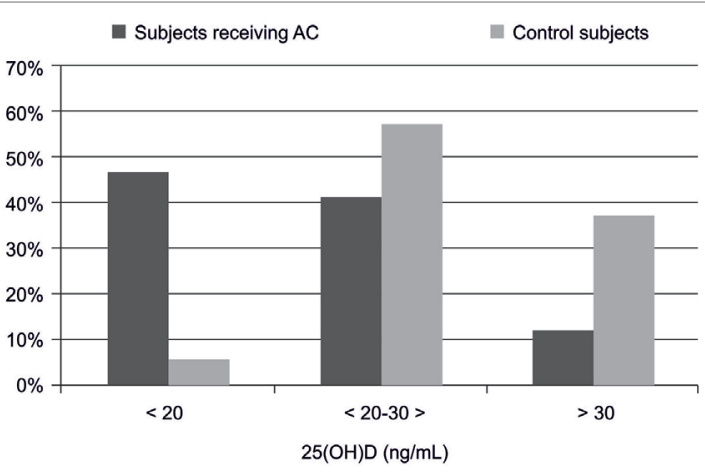

FIGURE 1 | The significant difference in percent distribution of 25(OH)D levels in subjects receiving acenocoumarol treatment and controls $(n=93)$.

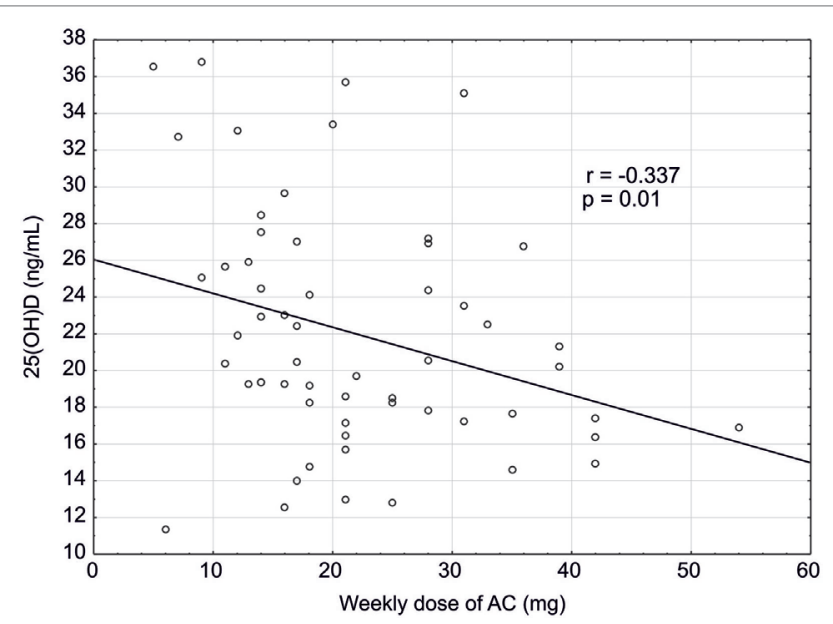

FIGURE 2 | Correlation between concentration of 25(OH)D (ng/mL) and a weekly dose of acenocoumarol $(\mathrm{mg})$ in studied patients $(n=58)$.

concentration of $25(\mathrm{OH}) \mathrm{D}<20 \mathrm{ng} / \mathrm{mL}$ indicating a deficiency, and the group of patients with a concentration of $25(\mathrm{OH})$ $\mathrm{D} \geq 20 \mathrm{ng} / \mathrm{mL}$. We did not find statistically significant differences in median age, BMI, time from last menstruation, the duration of treatment, and ALP activity between the groups. Both studied groups differed significantly in the median values of weekly dose of $\mathrm{AC}(p=0.045)$, the median of $25(\mathrm{OH}) \mathrm{D}$ concentration $(p<0.001)$, and proportion of female patients $(p=0.015)$ (Table 2).

\section{DISCUSSION}

The significantly decreased concentration of 25(OH)D observed in men and women treated with AC may indicate a potential negative effect of this therapy on vitamin $\mathrm{D}$ status, and presumably on bone metabolism or possible prospective health outcomes. Our results demonstrated that a large proportion of subjects receiving $\mathrm{AC}$ had vitamin $\mathrm{D}$ deficiency with the concentrations below $20 \mathrm{ng} / \mathrm{mL}$. Our results are consistent with the
TABLE 2 | Comparison of studied parameters, depending on 25(OH)D serum concentration in subjects treated with acenocoumarol (AC) (the cut-off value set at $20 \mathrm{ng} / \mathrm{mL}$ was used to define the deficiency level).

\begin{tabular}{|c|c|c|c|}
\hline Characteristics & $\begin{array}{l}\text { Subjects receiving } \\
\text { AC with } 25(\mathrm{OH}) \\
\text { D }<20 \mathrm{ng} / \mathrm{mL}\end{array}$ & $\begin{array}{l}\text { Subjects receiving } \\
\text { AC with } 25(\mathrm{OH}) \\
\text { D } \geq 20 \mathrm{ng} / \mathrm{mL}\end{array}$ & $p$ \\
\hline Number, $n$ & 27 & 31 & \\
\hline Age, years & $65(60 ; 73)$ & $65(59 ; 73)$ & NS \\
\hline $\begin{array}{l}\text { Gender (males/ } \\
\text { females), } n(\%)\end{array}$ & 8 (29.6)/19 (70.4) & $19(61.3) / 12(38.7)$ & 0.015 \\
\hline Body mass index, kg/m² & $27.9(24.8 ; 31.2)$ & $28.4(24.9 ; 32)$ & NS \\
\hline Post-menopause, years & $15(8.8 ; 24)$ & $15(8.5 ; 19.8)$ & NS \\
\hline $\begin{array}{l}\text { Smokers/non- } \\
\text { smokers, } n \text { (\%) }\end{array}$ & $3(11.1) / 24$ (88.9) & $8(25.8) / 23(74.2)$ & NS \\
\hline $\begin{array}{l}\text { Duration of } \mathrm{AC} \\
\text { treatment, years }\end{array}$ & $8(6 ; 10)$ & $10(7 ; 13)$ & NS \\
\hline Weekly dose of AC, mg & $21(17 ; 31)$ & $17(12 ; 28)$ & 0.045 \\
\hline Serum 25(OH)D, ng/mL & $17.2(14.8 ; 18.6)$ & $25.6(22.6 ; 29.6)$ & $<0.001$ \\
\hline ALP, IU/L & $62(58 ; 76)$ & $59(52 ; 74)$ & NS \\
\hline
\end{tabular}

Results are shown as median and quartiles (Q1; Q3).

results of other cross-sectional studies confirming the low level of vitamin $\mathrm{D}$ in patients receiving VKAs. For example, lower $25(\mathrm{OH}) \mathrm{D}$ levels in those taking VKAs were also seen in four cross-sectional studies performed among 514 Dutch females (21), 7,553 German males (22), 783 Netherlands geriatric outpatients (23), and 48 Greek children (24). On the contrary, in two other cross-sectional studies ( $n=127, n=116$, respectively) and one prospective cohort study $(n=167)$, no such associations were observed (25-27). Different recruitment methods, designs and methodologies, the influence of still unknown factors, or different duration of treatment may have caused such differences in results across studies presented above.

To the best of our knowledge, our study is the first to demonstrate the inverse association between the dose of $\mathrm{AC}$ and vitamin D levels, so there is limited possibility to compare our results with others. The possible relationship between the dose of VKA and the level of vitamin D may be confirmed by the recently published study on the treatment of vitamin $\mathrm{D}$ deficiency in patients with venous thromboembolism. The study showed that treatment of vitamin D deficiency in patients with venous thromboembolism, resulted in the control of the international normalized ratio with the lower doses of warfarin. This observation was the first clinical report of an enhancement of the anticoagulant effect of warfarin by vitamin D supplementation (28).

Some common mechanisms or overlapping pathways may be involved in the regulation of the biological effects of these two vitamins. Wang et al. have identified a novel CYP3A4dependent pathway, of 4-hydroxylation of 25-hydroxyvitamin $\mathrm{D}(3)$, the induction of which may contribute to drug-induced vitamin D deficiency. These results suggested that the CYP3A4dependent metabolism of vitamin $\mathrm{D}$ may be important for the regulation of vitamin $\mathrm{D}(3)$ levels in vivo and in the etiology of drug-induced osteomalacia (29). It is well known, that oxidative metabolism of isomer R-AC is catalyzed by several members of the cytochrome P-450 family in the liver, including CYP3A4. Those data, along with our observations, suggest a mechanism 
that leads to decreased vitamin D levels in patients on longterm VKA treatment. The interplay between vitamins $\mathrm{K}$ and $\mathrm{D}$ is apparent, for instance, in the form of osteocalcin, being essential for the formation of hydroxyapatite crystals in bone tissue $(30,31)$. Vitamin K2 can act not only through vitamin $\mathrm{K}$-dependent proteins, but is also able to directly impact the gene expression by binding to steroid and xenobiotic receptors (32). Furthermore, vitamin K and D overlap metabolically at the cellular level. The cyclic oxidation and reduction of vitamin $\mathrm{K}$ is a source of electron transfer for antioxidant power to protect living cells against oxidative stress (33). Similarly, 1,25(OH)D has anti-oxidative capacity, as demonstrated in animal studies (34). It can, therefore, be concluded that vitamins $\mathrm{K}$ and $\mathrm{D}$ interact and stimulate each other's metabolism. The activity of vitamin D metabolites can be regarded as a gatekeeper, controlling calcium absorption, while the activity of vitamin K2 can be seen as that of a traffic policeman, directing the calcium ions into the bone (35).

The major limitation of the study was the small sample size of recruited subjects, particularly of the control group (controls were not as numerous) and the observational design of the study, which did not allow us to draw conclusions about causality. Another limitation was the inability to assess concentration of parathormone and osteocalcin among participants. There was also the possibility that some subjects may have had lower vitamin D levels for reasons other than the treatment with AC. By way of example, individuals in poor physical condition are likely to spend more time indoors than healthy ones, thus are prone to inadequate natural ultraviolet B (UVB) exposure which could in turn lead to extremely limited skin synthesis of vitamin $\mathrm{D}$, and decreased $25(\mathrm{OH}) \mathrm{D}$ levels. The majority of the participants in this study were people actively working in their profession and none of the participants had a condition that would have made ambulating difficult, thus, in fact, time spent outdoors did not essentially affect the results. Nevertheless, neither the methodological issues nor other factors could detract from the main observation in this report. Our study revealed that AC doses negatively correlated with $25(\mathrm{OH}) \mathrm{D}$ concentrations, suggesting a possible association between VKA therapy and decreased vitamin $\mathrm{D}$ status. We also found that the median of weekly dose of AC was significantly higher in patients with lower vitamin D levels compared to patients with higher vitamin D levels. Further, patients in poor general physical condition do not generally receive higher doses of AC. Since our study was conducted during the winter months, when sunlight exposure was extremely low (latitude $53-54^{\circ} \mathrm{N}$ ), the potential impact of UVB on vitamin D status among studied participants may be

\section{REFERENCES}

1. Hollis BW. Assessment of vitamin D nutritional and hormonal status: what to measure and how to do it. Calcif Tissue Int (1996) 58:4-5. doi:10.1007/ BF02509538

2. Holick MF, Schnoes HK, DeLuca HF, Suda T, Cousins RJ. Isolation and identification of 1,25-dihydroxycholecalciferol. A metabolite of vitamin D active in intestine. Biochemistry (1971) 10:2799-804. doi:10.1021/bi00790a023

3. Atkins GJ, Anderson PH, Findlay DM, Welldon KJ, Vincent C, Zannettino AC, et al. Metabolism of vitamin D3 in human osteoblasts: evidence for autocrine regarded as irrelevant. Nevertheless, explanation of this phenomenon does require further study.

To summarize, the results obtained in this study may indicate that long-term therapy with AC may be related to low levels of vitamin $\mathrm{D}$. Thus far, a large number of data have been published regarding global consequences of vitamin $\mathrm{D}$ deficiency in the context of human morbidity, pleiotropic capacity, multifactorial associations between medical therapies, and vitamin D metabolism, in a variety of populations and risk groups (4). The general recommendations for vitamin D supplementation in healthy adult populations, although undergoing a vivid debate, are well known and commonly accepted, however, the list of populations at risk of deficiency have not yet been fully determined (18, 36-39). Future intervention studies warrant explanation and understanding of the underlying mechanisms of our findings, and may presumably allow the determination of precise recommendations for vitamin D-deficient patients treated with VKAs. Our observations, discussed above, suggest that 25-hydroxyvitamin D concentrations should be routinely measured and monitored in all patients receiving specifically long-term treatment with VKAs.

In conclusion, treatment with $\mathrm{AC}$ is associated with lower levels of 25-hydroxyvitamin D. Long-term administration of AC in adults may potentiate the risk of chronic vitamin $\mathrm{D}$ deficiency, thus, effective well-coordinated supplementation of vitamin D in these individuals needs careful consideration.

\section{ETHICS STATEMENT}

This study was carried out in accordance with the recommendations of the Declaration of Helsinki; written informed consent from all participants was obtained. Funded by Medical University of Bialystok. The Medical University of Bialystok in Poland approved the protocol (Approval: No. R-I-002/88/2013).

\section{AUTHOR CONTRIBUTIONS}

Design of the study: JS-P and JK. Data collection and analyses: JS-P, EJ, BZ-R, and WJ. Laboratory tests: BZ-R and WJ. Data evaluation: JS-P, JK, and EJ. Writing and preparation of the manuscript: JS-P, JK, EJ, and PA. Proof-reading and editing: JS-P, JK, EJ, and CS.

\section{FUNDING}

The study was funded by the Medical University of Bialystok (Grant No. 123-04641P).

and paracrine activities of 1 alpha, 25-dihydroxyvitamin D3. Bone (2007) 40:1517-28. doi:10.1016/j.bone.2007.02.024

4. Holick MF, Binkley NC, Bischoff-Ferrari HA, Gordon CM, Hanley DA, Heaney RP, et al. Evaluation, treatment, and prevention of vitamin D deficiency: an Endocrine Society clinical practice guideline. J Clin Endocrinol Metab (2011) 96:1911-30. doi:10.1210/jc.2011-0385

5. Silver J, Levi R. Regulation of PTH synthesis and secretion relevant to the management of secondary hyperparathyroidism in chronic kidney disease. Kidney Int Suppl (2005) 95:S8-12. doi:10.1111/j.1523-1755.2005. 09501.x 
6. Anderson PH, Atkins GJ, Turner AG, Kogawa M, Findlay DM, Morris HA. Vitamin D metabolism within bone cells: effects on bone structure and strength. Mol Cell Endocrinol (2011) 347:42-7. doi:10.1016/j.mce.2011.05.024

7. Centeno V, Picotto G, Pérez A, Alisio A, Tolosa de Talamoni N. Intestinal $\mathrm{Na}(+) / \mathrm{Ca}(2+)$ exchanger protein and gene expression are regulated by $1,25(\mathrm{OH})(2) \mathrm{D}(3)$ in vitamin D-deficient chicks. Arch Biochem Biophys (2011) 509:191-6. doi:10.1016/j.abb.2011.03.011

8. Duque G, El Abdaimi K, Henderson JE, Lomri A, Kremer R. Vitamin D inhibits Fas ligand-induced apoptosis in human osteoblasts by regulating components of both the mitochondrial and Fas-related pathways. Bone (2004) 35:57-64. doi:10.1016/j.bone.2004.03.005

9. Schurgers LJ, Aebert H, Vermeer C, Bültmann B, Janzen J. Oral anticoagulant treatment: friend or foe in cardiovascular disease? Blood (2004) 104:3231-2. doi:10.1182/blood-2004-04-1277

10. Koos R, Mahnken AH, Mühlenbruch G, Brandenburg V, Pflueger B, Wildberger JE, et al. Relation of oral anticoagulation to cardiac valvular and coronary calcium assessed by multislice spiral computed tomography. Am J Cardiol (2005) 96:747-9. doi:10.1016/j.amjcard.2005.05.014

11. Weijs B, Blaauw Y, Rennenberg RJ, Schurgers LJ, Timmermans CC, Pison L, et al. Patients using vitamin $\mathrm{K}$ antagonists show increased levels of coronary calcification: an observational study in low-risk atrial fibrillation patients. Eur Heart J (2011) 32:2555-62. doi:10.1093/eurheartj/ehr226

12. Krüger T, Oelenberg S, Kaesler N, Schurgers LJ, van de Sandt AM, Boor P, et al. Warfarin induces cardiovascular damage in mice. Arterioscler Thromb Vasc Biol (2013) 33:2618-24. doi:10.1161/ATVBAHA.113.302244

13. Tufano A, Coppola A, Contaldi P, Franchini M, Minno GD. Oral anticoagulant drugs and the risk of osteoporosis: new anticoagulants better than old? Semin Thromb Hemost (2015) 41:382-8. doi:10.1055/s-0034-1543999

14. Gorski JP. Biomineralization of bone: a fresh view of the roles of non-collagenous proteins. Front Biosci (Landmark Ed) (2011) 16:2598-621. doi:10.2741/3875

15. Grey A, Bolland M, Cundy T. Maintaining order in osteoporosis treatments. J Bone Miner Res (2017) 32:1147. doi:10.1002/jbmr.3127

16. Furie B, Bouchard BA, Furie BC. Vitamin K-dependent biosynthesis of gamma-carboxyglutamic acid. Blood (1999) 93:1798-808.

17. Holick MF. Vitamin D deficiency. NEnglJ Med (2007) 357:266-81. doi:10.1056/ NEJMra070553

18. Pludowski P, Holick MF, Grant WB, Konstantynowicz J, Mascarenhas MR, Haq A, et al. Vitamin D supplementation guidelines. J Steroid Biochem Mol Biol (2018) 175:125-35. doi:10.1016/j.jsbmb.2017.01.021

19. Ushiroyama T, Ikeda A, Ueki M. Effect of continuous combined therapy with vitamin $\mathrm{K}(2)$ and vitamin $\mathrm{D}(3)$ on bone mineral density and coagulofibrinolysis function in postmenopausal women. Maturitas (2002) 41:211-21. doi:10.1016/S0378-5122(01)00275-4

20. Knapen MH, Schurgers LJ, Vermeer C. Vitamin K2 supplementation improves hip bone geometry and bone strength indices in postmenopausal women. Osteoporos Int (2007) 18:963-72. doi:10.1007/s00198-007-0337-9

21. Sohl E, van Schoor NM, de Jongh RT, de Vries OJ, Lips P. The impact of medication on vitamin D status in older individuals. Eur J Endocrinol (2012) 166:477-85. doi:10.1530/EJE-11-0917

22. Ernst JB, Kuhn J, Becker T, Dreier J, Börgermann J, Knabbe C, et al. Association between circulating 25-hydroxyvitamin D levels and medication use in patients scheduled for cardiac surgery. Nutri Metab Cardiovasc Dis (2015) 25:280-6. doi:10.1016/j.numecd.2014.10.014

23. van Orten-Luiten AC, Janse A, Dhonukshe-Rutten RA, Witkamp RF. Vitamin $\mathrm{D}$ deficiency as adverse drug reaction? A cross-sectional study in Dutch geriatric outpatients. Eur J Clin Pharmacol (2016) 72:605-14. doi:10.1007/s00228016-2016-2

24. Avgeri M, Papadopoulou A, Platokouki H, Douros K, Rammos S, Nicolaidou P, et al. Assessment of bone mineral density and markers of bone turnover in children under long-term oral anticoagulant therapy. J Pediatr Hematol Oncol (2008) 30:592-7. doi:10.1097/MPH.0b013e31817541a8

25. Sato Y, Honda Y, Kunoh H, Oizumi K. Long-term oral anticoagulation reduces bone mass in patients with previous hemispheric infarction and nonrheumatic atrial fibrillation. Stroke (1997) 28:2390-4. doi:10.1161/01.STR. 28.12.2390

26. Stenova E, Steno B, Killinger Z, Baqi L, Payer J. Effect of long-term oral anticoagulant therapy on bone mineral density and bone turnover markers: a prospective 12 month study. Bratisl Lek Listy (2011) 112:71-6.

27. Sato Y, Honda Y, Jun I. Long-term oral anticoagulation therapy and the risk of hip fracture in patients with previous hemispheric infarction and nonrheumatic atrial fibrillation. Cerebrovasc Dis (2010) 29:73-8. doi:10.1159/ 000256650

28. Hejazi ME, Modarresi-Ghazani F, Hamishehkar H, Mesgari-Abbasi M, Dousti S, Entezari-Maleki T. The effect of treatment of vitamin D deficiency on the level of P-selectin and hs-CRP in patients with thromboembolism: a pilot randomized clinical trial. J Clin Pharmacol (2017) 57:40-7. doi:10.1002/ jcph.774

29. Wang Z, Lin YS, Zheng XE, Senn T, Hashizume T, Scian M, et al. An inducible Cytochrome P450 3A4-dependent vitamin D catabolic pathway. Mol Pharmacol (2012) 81:498-509. doi:10.1124/mol.111.076356

30. Ferland G. The vitamin K-dependent proteins: an update. Nutr Rev (1998) 56:223-30. doi:10.1111/j.1753-4887.1998.tb01753.x

31. Booth SL, Broe KE, Peterson JW, Cheng DM, Dawson-Hughes B, Gundberg CM, et al. Associations between vitamin K biochemical measures and bone mineral density in men and women. J Clin Endocrinol Metab (2004) 89:4904-9. doi:10.1210/jc.2003-031673

32. Zhou C, Verma S, Blumberg B. The steroid and xenobiotic receptor (SXR), beyond xenobiotic metabolism. Nucl Recept Signal (2009) 7:e001. doi:10.1621/ nrs.07001

33. Li J, Wang H, Rosenberg PA. Vitamin K prevents oxidative cell death by inhibiting activation of 12-lipoxygenase in developing oligodendrocytes. J Neurosci Res (2009) 87:1997-2005. doi:10.1002/jnr.22029

34. Chen KB, Lin AM, Chiu TH. Systemic vitamin D3 attenuated oxidative injuries in the locus coeruleus of rat brain. Ann N Y Acad Sci (2003) 993:313-24. doi:10.1111/j.1749-6632.2003.tb07539.x

35. Hoenderop JG, Nilius B, Bindels RJ. ECaC: the gatekeeper of transepithelial Ca2+ transport. Biochim Biophys Acta (2002) 1600:6-11. doi:10.1016/S15709639(02)00438-7

36. Dawson-Hughes B, Mithal A, Bonjour JP, Boonen S, Burckhardt P, Fuleihan GE, et al. IOF position statement: vitamin D recommendations for older adults. Osteoporos Int (2010) 21:1151-4. doi:10.1007/s00198-010-1285-3

37. Rosen CJ, Abrams SA, Aloia JF, Brannon PM, Clinton SK, Durazo-Arvizu RA, et al. IOM committee members respond to Endocrine Society vitamin D guideline. JClin Endocrinol Metab (2012) 97:1146-52. doi:10.1210/jc. 2011-2218

38. Pludowski P, Karczmarewicz E, Bayer M, Carter G, Chlebna-Sokół D, CzechKowalska J, et al. Practical guidelines for the supplementation of vitamin D and the treatment of deficits in Central Europe - recommended vitamin D intakes in the general population and groups at risk of vitamin D deficiency. Endokrynol Pol (2013) 64:319-27. doi:10.5603/EP.2013.0012

39. Pludowski P, Ducki C, Konstantynowicz J, Jaworski M. Vitamin D status in Poland. Pol Arch Med Wewn (2016) 126:530-9. doi:10.20452/pamw.3479

Conflict of Interest Statement: The authors declare that the research was conducted in the absence of any commercial or financial relationships that could be construed as a potential conflict of interest.

The reviewer EC and handling Editor declared their shared affiliation.

Copyright (C) 2018 Sawicka-Powierza, Konstantynowicz, Jablonska, ZelazowskaRutkowska, Jelski, Abramowicz, Sasinowski and Chlabicz. This is an open-access article distributed under the terms of the Creative Commons Attribution License (CC BY). The use, distribution or reproduction in other forums is permitted, provided the original author(s) and the copyright owner are credited and that the original publication in this journal is cited, in accordance with accepted academic practice. No use, distribution or reproduction is permitted which does not comply with these terms. 